\title{
Treatment decisions following assessment by multidisciplinary psychogeriatric teams
}

\author{
James Lindesay, Joe Herzberg, Gill Collighan, \\ Alastair Macdonald and Michael Philpot
}

\begin{abstract}
The peychioitic treatment declisions mads by two multidisciplinary peychogeriatilic teams in 100 now referrals were compared with those made by a group of poychictitats following independent formal resecreh asecesments. There was sefteflactory agreement between the feam and resecarch dectitons with regard to poychlatilic hospltat admistion, antidepresiant treafment and neurolepilic treatment. Agreement was less good for poychological treatments.
\end{abstract}

Increasingly, specialist psychiatric services for elderly people in the United Kingdom are being provided by community based multidisciplinary teams (Jolley \& Arie, 1992). In some of these teams, a proportion of the initial patient assessments are carried out by non-doctors, and concern has been expressed that this may result in a second-class service, compared to those in which the initial assessment is always carried out by a psychogeriatrician (Jolley, 1993). In a comparison of the diagnostic performance of two teams operating the model of multidisciplinary assessment with formal psychiatric assessment and diagnosis by an independent research group. it was shown that the multidisciplinary approach is not associated with any significant misdiagnosis of psychiatric disorder (Collighan et al, 1993). However, it is important that other aspects of the activity of such teams, such as treatment and outcome, are also examined. In this paper we describe decisions about psychiatric treatments made following team assessments and compare them with those recommended by independent research psychiatrists.

\section{The study}

The London Borough of Lewisham is served by two multidisciplinary community teams for mental health in the elderly which provide comprehenstve assessment, treatment, rehabilitation and support services to elderly mentally 111 people living in the area. Both teams operate an open referral system, and accept referrals from a wide range of agencies. Initial domiciliary assessments are carried out by either a medical or non-medical team member using a semi-structured assessment schedule, and all cases are presented and discussed at a weekly team meeting where an initial diagnosis is made and a management plan formulated. The progress of these cases is also reviewed regularly by the teams.

A full account of the methodology of this study is given by Collighan et al (1993). Three hundred and seventy-eight new cases were referred to the teams between May 1990 and February 1991, and the study sample consisted of the $100(26 \%)$ who could be interviewed within one week of referral. These cases were independently and blindly assessed by a research psychiatrist. The research assessment in all cases consisted of the Geriatric Mental State (Copeland et al, 1976), a full medical and psychiatric history, a physical examination, and a routine blood screen. Where possible, a collateral history from relevant informants was also obtained. The findings of the research assessments were presented by the research psychiatrist to two independent consultant psychogeriatricians who were also blind to the teams' assessments and treatment decisions, and a consensus research psychiatric diagnosis and shadow management plan were agreed for each case. The specific aspects of management examined in this analysis are: psychiatric hospital admission; antidepressant treatment; use of neuroleptics; and psychological treatments (supportive psychotherapy, cognittivebehavioural therapy, bereavement therapy). Six weeks after initial assessment by the teams, the patients' case notes were reviewed by the research psychiatrist and all management decisions made over this period were recorded. These were compared with the shadow management plans agreed by the three research psychiatrists at their consensus meeting. The study data were analysed using SPSS/PC+ (SPSS, 1986). Agreements between the actual and the shadow 
Table 1. Team and research diagnoses $(n=100)$

\begin{tabular}{lccc}
\hline & $\begin{array}{l}\text { Team } \\
\text { diagnoses }\end{array}$ & $\begin{array}{l}\text { Resecich } \\
\text { dilagnoses }\end{array}$ & Kappa \\
\hline Non-case & 3 & 2 & 0.80 \\
Dementia & 55 & 63 & 0.79 \\
Delirium & 4 & 3 & 0.56 \\
Depression & 34 & 31 & 0.89 \\
Mania & 2 & 3 & 0.80 \\
Anxiety & 2 & 1 & 0.66 \\
Paranold state & 3 & 4 & 0.85 \\
\hline
\end{tabular}

management plans were quantified by means of percentage agreements and the kappa statistic (к).

\section{Findings}

The age range of the study sample was 65-90 years (mean $78.2 \pm 6.64$ years). There were 70 women and 30 men. Of the cases, $67 \%$ were assessed initially by a non-medical team member. The sample was representative of the total number of new referrals to the teams during the study period in terms of age distribution, sex ratio and team diagnoses. The proportion of study cases initially assessed by senior (non-training grade) psychiatrists was lower in the study sample (7\% v. 20\%). The diagnoses made by the teams and the researchers in the study sample are shown in Table 1; the diagnostic agreement between the teams and the researchers is discussed in Collighan et al (1993). The agreements between teams and researchers with regard to specific treatment decisions are summarised in Table 2.

\section{Psychiatric hospital admission}

Eighteen of the study patients were admitted to the area psychiatric in-patient unit following initial assessment and discussion by the teams. The researchers also recommended psychiatric admission in 18 cases, and agreed with the teams in eleven cases $(k=0.53)$. The seven cases not admitted by the teams were managed in a variety of alternative ways, including geriatric referral, recommendations for residential placement and medication with follow-up at home. Two of these cases were diagnosed as manic by both teams and researchers; they both received neuroleptic medication and were referred to the geriatrician for further management of underlying medical problems. In the seven cases admitted by the teams where the researchers disagreed, the latter recommended a variety of alternatives, including further assessment by the team, geriatric referral, placement in residential care, and treatment at home.

\section{Antidepressant treatment}

Overall, 26 of the study patients were started on antidepressant medication following team assessment. The research psychiatrists recommended this form of treatment in 19 cases, and there was agreement between the team and research decisions in 16 cases $(x=0.63)$. Two of the team patients were also started on lithium prophylaxis in the six-week period after assessment, and one received a course of electroconvulstve therapy (ECT). These treatment options were not recommended in any case by the researchers. In three cases where antidepressant treatment was recommended by the researchers but not given by the team, two recetved cognittve-behavioural therapy instead, and one was placed into residential care.

Table 2. Agreement between team and research management decisions $(n=100)$

\begin{tabular}{lllll}
\hline & Team & Research & Agreement (\%) & Kappa \\
\hline Psychiatric admission & 18 & 18 & 86 & 0.53 \\
Antidepressants & 26 & 19 & 87 & 0.63 \\
Neuroleptics & 17 & 13 & 90 & 0.61 \\
Uthlum & 2 & 0 & 98 & 0 \\
Electroconvulsive therapy & 1 & 0 & 99 & 0 \\
Psychological treatments & 18 & 18 & 82 & 0.39 \\
Psychotherapy & 9 & 15 & 86 & 0.34 \\
Cognittive-behavioural therapy & 6 & 1 & 95 & 0.32 \\
Bereavement therapy & 3 & 2 & 97 & 0.49 \\
\hline
\end{tabular}




\section{Use of neuroleptics}

Neuroleptic medication was prescribed to 17 of the patients. The researchers recommended this treatment option in 13 cases, agreeing with the team decisions in 10 cases $(x=0.61$ ). Four cases were diagnosed elther by the team or the researchers as suffering from schizophrenia or a paranoid state, and in three the treatment decisions agreed: two recetved additional neuroleptic medication and one did not. Of the 54 cases diagnosed by both the teams and the researchers as having dementia, twelve recetved neuroleptic medication. The researchers recommended this treatment in seven cases, agreeing with the team in each case $(x=0.69)$.

\section{Psychological treatments}

Some form of psychotherapeutic intervention was started in 18 cases. The researchers also recommended these approaches in 18 cases, agreeing with the team decision in nine $(k=0.39)$. There was agreement as to the precise form of intervention in six of these cases. Overall, agreement was greatest for bereavement therapy and least for cognittive-behavioural therapy. In all of the nine cases where the researchers recommended psychological treatment but this was not provided by the teams, the treatment in question was supportive psychotherapy.

\section{Comment}

Management decisions made by the teams following assessment involved much more than the psychiatric interventions examined in this study, and included referral to geriatric services, referral to social services, recommendations for residential care, and carer support. This analysis is limited to psychiatric treatments because the research assessment was itself limited to a clinical psychiatric evaluation, and because the researchers' decisions about management were inevitably made without reference to the periodic constraints on the service such as avallability of social care, appropriate residential provision and accessible medical and surgical services that influenced the practice of the teams over the study period. The aim of this study was not to measure the performance of the teams against a gold standard of clinical psychiatric judgement (such a thing does not exist), but to describe the decisions about psychiatric treatment made following assessment by this form of service and compare them with those that might have been made following a specifically psychiatric assessment of the cases. It should be emphasised that disagreement does not imply poor practice on the part of the teams, since they may be equipped to manage cases in different ways that avoid conventional or unavailable interventions such as admission to hospital or residential care.

With these considerations in mind, there appear to be varying levels of agreement between the teams and the researchers with regard to the decisions about specific treatments. There was good agreement with regard to antidepressant use, with teams and researchers agreeing in $87 \%$ of cases. Only three patients identified by the researchers as needing this did not recetve it; they were all diagnosed as depressed by the team and managed by alternative behavioural or social means. Whether or not this degree of disagreement is significant in terms of outcome requires further study. Overall, the teams were blased in favour of physical treatments compared to the researchers, perhaps because psychological and social alternattves were less available to them than in the ideal service imagined by the researchers, or because the teams were more orlented towards medical rather than non-medical interventions. The lack of any recommendations by the researchers with regard to lithium prophylaxis or ECT is because these decisions would have depended on the outcome of investigations and further assessment not carried out as part of the research assessment.

There was also satisfactory agreement between teams and researchers with regard to the use of neuroleptic medication, both in demented patients and in those suffering from schizophrenia or a paranoid state. The use of neuroleptics in managing disturbed behaviour in dementia is controversial, and the problems caused by excessive sedation and extrapyramidal side effects need to be balanced against the advantages of staying at home if the only alternative is admission to residential or hospital care. In this study. the teams and the researchers appear to have broadly agreed on the balance of risks and benefits of these options.

There was less agreement with regard to psychological interventions. This was not the result of any bias in favour of greater or lesser use of these approaches by the teams; they were provided at the same rate as recommended by the researchers, but to a rather different group of patients. Again, specific management decisions by the teams were probably influenced by the resources available at the time, particularly with regard to supporttve psychotherapy, which is a time-consuming activity for team members with a heavy workload.

In conclusion, the findings of this study did not find any evidence that the multidisciplinary assessment process carried out by these teams resulted in substantial under-use or inappropriate use of psychiatric interventions. However. only a formal evaluation of outcomes can determine whether or not this approach to 
assessment and management is as effective as the more traditional medical model.

\section{References}

COLUGHAN, G., MACDONALD, A., HerZBERg. J., et al (1993) An evaluation of the multidisciplinary approach to poychiatric diagnosis in elderty people. British Medical Journal, S06, 821-824.

Copeland, J. R. M., Keueher, M. J., Keuet, J. M., et al (1976) A semi-structured interview for the assessment and diagnosis and mental state in the elderty: the gerlatric mental state schedule: development and reliability. Psychological Medictne, 6, 439-449.

JouEY, D. (1993) Psychiatry services for elderly people: doctors should be in the front line. British Medical Joumal, S08, 1411.

- \& ARIE, T. (1992) Developments in psychogeriatric services. In Recent Aduances in Psychogeriatrics, Vol. 2 (Ed. T. Arie). London: Churchill Livingstone.
SPSS (1986) Statistical Package for the Soctal Sclences. Chicago: SPSS.

* James Lindesay. Professor of Psychiatry for the Elderly, University of Leicester, Leicester General Hospital, Gwendolen Road, Leicester LE5 4PW; Joe Herzberg. Consultant and Senior Lecturer in Psychiatry of Old Age, U.M.D.S., London SE1 9RT, Gill Colligan, Senior Registrar in Psychiatry, The Bethlem and Maudsley Hospitals, London: Alastair Macdonald, Consultant and Senior Lecturer in Psychiatry of Old Age, U.M.D.S. London SE1 9RT, and Michael Philpot, Consultant and Senior Lecturer in Psycho geriatrics. The Bethlem and Maudsley Hospitals, London SE1 9RT

"Correspondence

\title{
DEFEAT DEPRESSION CAMPAIGN FUN RUN \\ BATTERSEA PARK, LONDON
}

\author{
11 a.m. Sunday 28th April 1996 \\ Entry Fee $£ 3.00$ Distance $2 \frac{1}{2}$ miles
}

All proceeds to go towards the production of

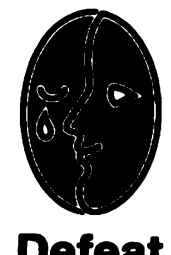

Defeat Depression
Defeat Depression Campaign

educational material

For an entry form please contact

Christine Gear on 01712352351 ext 131

A National Campaign onganised by

The Royal College of Psychiatrists in association with

The Royal College of General Practitioners 